\title{
FATAL METHANOL INGESTION IN A CHILD: CASE REPORT
}

\author{
Nursel Türkmen ${ }^{1}$, Bulent Eren², Gürsel Cetin ${ }^{3}$ \\ Uludag University Medical Faculty, Forensic Medicine Department, Council of Forensic Medicine of Turkey Bursa \\ Morgue Department, Bursa, Turkey ${ }^{1}$; Council of Forensic Medicine of Turkey Bursa Morgue Department, Bursa, Turkey²; \\ Istanbul University Medical Faculty, Forensic Medicine Department, Council of Forensic Medicine of Turkey, Istanbul \\ Morgue Department ${ }^{3}$
}

Summary: The records of Forensic Medicine Council of Turkey Bursa Morgue Department reveal the first case of fatal methanol ingestion in a child. Household methanol exposures are mostly due to accidental ingestion of washing fluids. A 4 year-old girl was admitted to the emergency department with her parents with gastrointestinal symptoms; nausea, vomiting and abdominal pain. Toxicological studies revealed $79 \mathrm{mg} / \mathrm{dl}$ blood level of methanol. We presented infant autopsy case of methanol toxicity and discussed the case from medicolegal aspect.

Key words: Child; Methanol; Death; Forensic autopsy

\section{Introduction}

Household methanol exposures are mostly due to accidental ingestion of washing fluids. But rare exposures also have occurred through dermal and pulmonary routes, which cases are reported usually in occupational areas (1, $3,6,7)$. The diagnosis often needs a high index of suspicion, because treatment is available and it is important to recognize methanol poisoning instantly (6). We presented autopsy case of 4 year-old girl without clear initial signs or symptoms of methanol toxicity.

\section{Case report}

The records of Forensic Medicine Council of Turkey Bursa Morgue Department reveal the first case of fatal methanol ingestion in a child. A 4 year-old girl was admitted to the emergency department with her parents with gastrointestinal symptoms nausea, vomiting and abdominal pain. Where patient short time after medical examination suddenly confused and transported to University Hospital. Upon arrival at the triage; drowsiness, confusion, pupils fixed dilated and Glasgow Coma Scale: 3 were observed. Also severe anion gap metabolic acidosis, high liver enzymes: Serum Aspartate Aminotransferase: $234 \mathrm{mg} / \mathrm{dl}$, Serum Alanine Aminotransferase: $71 \mathrm{mg} / \mathrm{dl}$, Serum Creatine Kinase: $424 \mathrm{mg} / \mathrm{dl}$ were detected. Radiological evaluation revealed brain edema. Case was evaluated and treated as metabolic disorder or intoxication. Biochemical screening for Teophiline, Carbamazepine, Phenytoin, Lithium and Salicylate were performed but results were negative. Her family members stated that she was healthy and had not been ever medically evaluated. According to the police documentation and investigation, parents remembered that girl had been ingested washing fluid stored in a bottle two days ago as her sister newly declared. When the criminal investigation was expanded it was learned that the initiation of symptoms like abdominal pain had duration of two days. The careless attitudes of the parents interested detectives, then the parents acknowledged that they were informally divorced, separate living and that the care of children was in responsibility of grandmothers. For this reason they stated that they have had not information about ingestion of washing fluid because they were labor shift working persons, and also claimed that they worried about their girl, also for the legal aspects of child neglect. The victim was taken to the Forensic Council Bursa Morgue Department for further examination. On gross physical examination, there were; needle puncture sites on the back of the hands and the cubital fossas and $2 \mathrm{~cm}$ minilaparotomy incision on abdominal wall. Autopsy macroscopic examination revealed petechial haemorrhages on lung surfaces and internal organs. Histology of internal organs confirmed the gross findings. During the valuable initial period the case was evaluated and treated as metabolic disorder, because biochemical analysis for methanol was not performed, as the consequence of missing clinical data of methanol ingestion. The final diagnosis of methanol poisoning was demonstrated by toxicological analysis after autopsy, two days after ingestion of washing fluid. Toxicological studies after autopsy revealed $79 \mathrm{mg} / \mathrm{dl}$ blood level of methanol. We presented infant autopsy case of methanol toxicity, discussed the case from medicolegal aspect. 


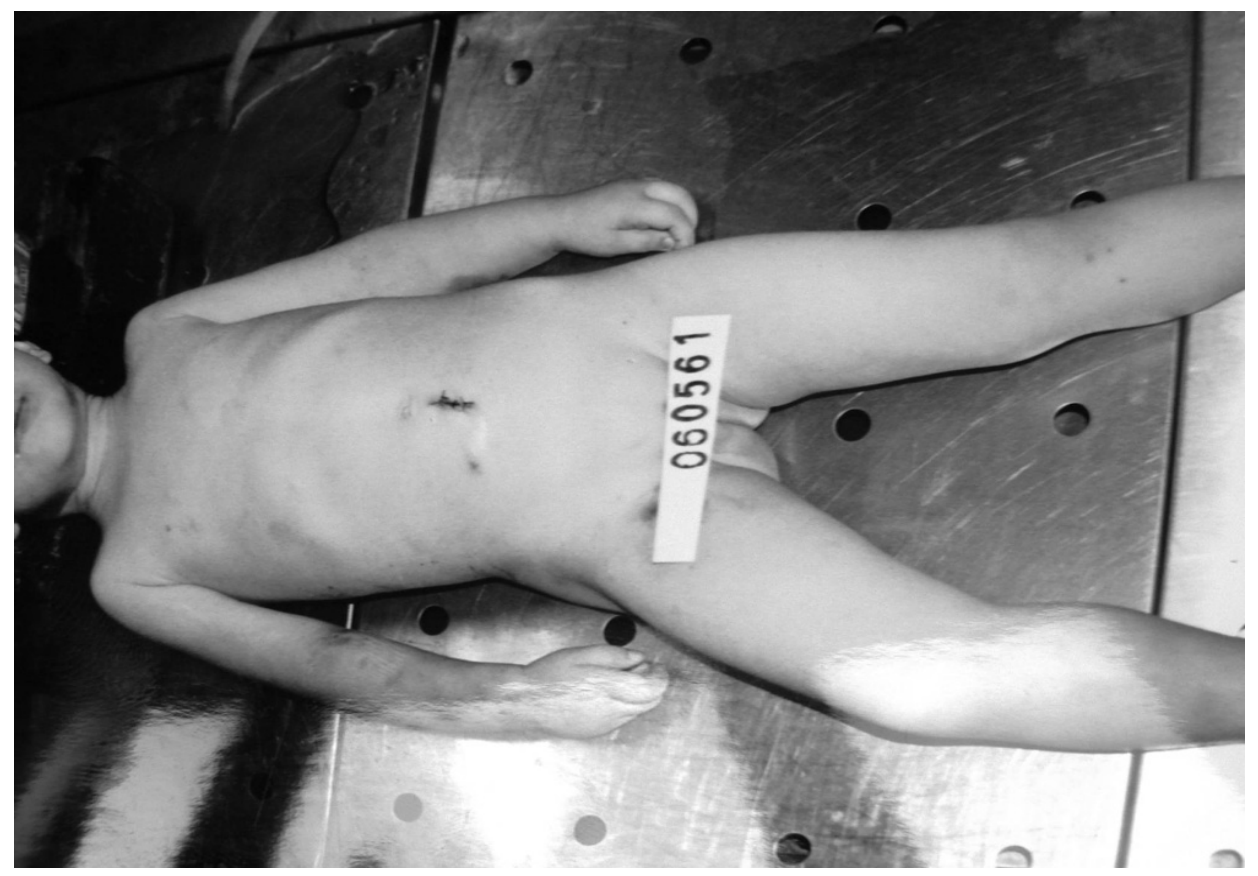

Fig. 1: Gross external examination; laparotomy incision on abdominal wall.

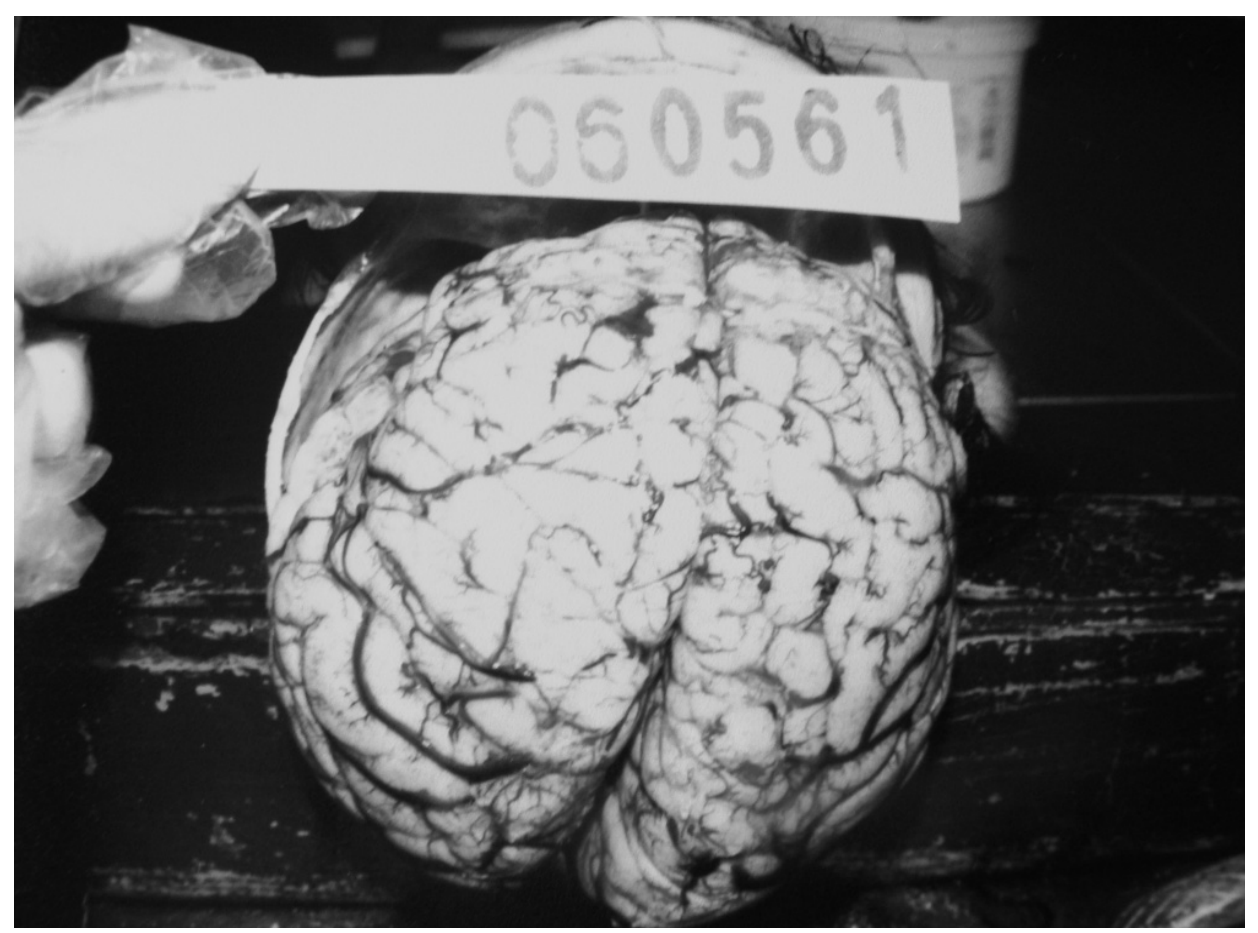

Fig. 2: Severe brain edema, flattened brain surface with widened gyri and congested vessels. 


\section{Discussion}

Household methanol exposures are mostly due to accidental ingestion of washing fluids. But rare exposures also have occurred through dermal and pulmonary routes, which cases are reported usually in occupational areas (1, $3,6,7)$. The lethal dose of methanol is reported as 1 to 2 $\mathrm{mL} / \mathrm{kg}$. Ingestion of a little amount as $0.1 \mathrm{~mL} / \mathrm{kg}$ has reported to be resulted in permanent blindness or death (1). Methanol is rapidly absorbed via the gastrointestinal tract. Most household exposures are due to the intentional or accidental ingestion of windshield washing fluids and fuel de-icing agents, cases would be seen more commonly in occupational settings (1). In the literature from USA it was demonstrated that most accidental exposures were reported in children younger than 6 years, like our case, wheres half of the cases of exposure were reported in children ranging from 6 to 19 years of age (3). Davies et al. (4) also indicated that toddlers were at the highest risk cluster for methanol exposure, but on the other hand adolescents and adults were at the highest risk for life-threatening intoxications in concert with investigation of clinical documents of different study which also revealed that outcomes data in toddlers resulted in comlete treatment with no sequelae (3). Drowsiness, confusion, ataxia, ocular injury, blindness, coma, seizure, and hypotension may be observed (1-7). Methanol toxicity has a more significant manifestation in that it affects the optic system more so than any of the other toxic alcohols. Different patients may report variable degrres of visual symptoms like looking though a snow field, but in the presented case there were no documentation about visual symptoms. Other ophthalmic effects include mydriasis, papilledema, retinal edema, and hyperemia of the optic disc
(1). These signs and symptoms are able to be seen in varying degrees and are related to the amount and time of methanol ingestion. Mortality is often associated in settings where treatment was not initiated quickly or correctly as it was in the presented case (1-7). Meyer et al. stated that some patients, in spite of potentially lethal methanol levels of up to $160 \mathrm{mmol} / \mathrm{L}$, did not develop signs of toxicity (5). Different from the presented case blood methanol levels were above $100 \mathrm{mg} / \mathrm{dL}$ in majority $(70 \%)$ of their cases in the study of Davies et al. (4), but similar to our findings metabolic acidoses and anion gap were detected in most of the cases.

The patient presented without signs or symptoms of methanol toxicity is suggested to demonstrate difficulties during evaluation process. For these reason, for the patient who has been poisoned with methanol without evidence of clinical toxicity, the first primacy is to provide specific therapy which can probably decrease the morbidity and mortality associated with this form of poisoning.

\section{References}

1. Barceloux DG, Bond GR, Krenzelok EP, Copper H, Vale JA. American Academy of Clinical Toxicology Practice Guidelines on the Treatment of Methanol Poisoning. J Toxicol Clin Toxicol 2002;40:415-46.

2. Brown MJ, Shannon MW, Woolf A, Boyer EW. Childhood methanol ingestion treated with fomepizole and hemodialysis. Pediatrics. 2001;108:E77.

3. Bucaretchi F, Baracat E. Acute toxic exposure in children: an overview. J Pediatri (Rio J) 2005;81(5 Suppl):S212-22.

4. Davis LE, Hudson D, Benson BE, Jones Easom LA, Coleman JK. Methano poisoning exposures in the United States: 1993-1998. J Toxicol Clin Toxicol. 2002;40:499-505

5. Kruse JA. Methanol poisoning. Intensive Care Med. 1992;18:391-7.

6. Meyer RJ, Beard ME, Ardagh MW, Henderson S. Methanol poisoning. N Z Med J. 2000;113:11-13.

7. Watson WA, Litovitz TL, Rodgers Jr GC, et al. 2004 Annual report of the American Association of Poison Control Centers Toxic Exposure Surveillance System. Am J Emerg Med 2005;23:589-666.

\section{Corresponding author:}

Dr. Bülent Eren, Council of Forensic Medicine of Turkey Bursa Morgue Department, Heykel, Osmangazi 16010, Bursa, Turkey; e-mail: bulenteren2000@yahoo.com. 